\title{
Modelling Discretionary: The Development of Automated Financial Service Industry
}

\author{
Xiaomin Guo ${ }^{1}$ \\ ${ }^{1}$ College of Business, Pacific University, USA \\ Correspondence: Xiaomin Guo, College of Business, Pacific University, USA. E-mail: xguo@pacificu.edu
}

Received: September 23, 2016

Accepted: October 19, 2016 Online Published: November 20, 2016

doi:10.5539/ijef.v8n12p44

URL: http://dx.doi.org/10.5539/ijef.v8n12p44

\begin{abstract}
This research focuses on modeling the investment manager behavior in investments planning, and explores the trend of the current human-based financial planning industry. In the recent decade, the replacement of human financial service with automated financial solution grows rapidly. This paper provides a model of automated investments procedure to detect the possibility of substituting the human-based portfolio management with a machine-dominated process. The major contribution of this research is the algorithm of discretionary, which is the major obstacle of the machine-based portfolio control. The conclusion of this paper can serve as the logic flow of the investment management program.
\end{abstract}

Keywords: automated, financial planning, portfolio management, investment, human behavior

\section{Introduction}

Financial services automation is a critical issue in today's competitive business environment. The automation of financial services industry can help the decision makers to make more informed decisions and can help the customers to match available financial products to their needs with a higher degree of accuracy and confidence (Ansari \& Riasi, 2016).

There are three aspects of financial industry automation. Financial industry automation at the buy side refers to the automated investment decision making and portfolio management. Financial industry automation at the sell side refers to the automated risk control and fair value pricing models. Financial industry automation is also widely implemented in the transaction and exchange process.

The sell side automation has the lowest degree of development by far. This is less because of the difficulty of modeling discretionary at asset pricing during the financing process, but more due to the advantages of human beings' non-repeatable and non-linear asset pricing competence that computer algorithms can never replicate. For example, the premiums of controlling interest, the off-balance-sheet asset valuation, and the management value beyond goodwill are all associated with the human characteristics of the transaction counterparties. Such ad hoc valuation process cannot be repeated with the same outcome being generated. Therefore, computer algorithms fail to beat human being in this area which falls outside of the scope of science and mathematics.

The exchange automation has the highest degree of implementation. This is because machines in this area have unarguable advantages compared to human traders: being fast, precise, fair, transparent, error-free, and full-time, etc. This is also because exchange automation is the easiest to implement. Open-outcry mechanism used to be the signature of exchange trading. But now, it is more like a culture heritage in finance history. "Stock, futures and options exchanges worldwide are shifting from conventional open-outcry markets to electronic trading," (Shah \& Brorsen, 2011) not only in terms of matching positions, but also in terms of implementing trading strategies. Even though large traders still prefer outcry trading (Shah \& Brorsen, 2011), there is a trend of electronic trading in all senses which is too significant to be ignored.

One may argue that the buy side automation has a long and well-developed track record, too. The automated asset selection algorithms, trading orders, high-frequency trading models all appear to be the examples of the development of the buy side automation. However, asset selection and execution only makes up a little fraction of a buy side decision, though the industry and academia have generated massive algorithms in asset selection, much portion of the buy side process is left out. The examples of the previous work on automated asset selection are: Cartea and Jaimungal (2016) work on the optimal investment strategy for an agent who maximizes expected 
utility of wealth by dynamically trading in cointegrated assets. Cartea, Donnelly, and Jaimungal (2014) work on the algorithmic trading with model uncertainty that allows for ambiguity in traders choices to make the trading models robust to misspecification.

The buy side processes before asset selections that are missed by the automated trading are: risk profile testing, return target and demand testing, liquidity consideration, legal concerns planning, tax planning, term planning, and unique needs of the clients. The buy side processes after asset selections that are missed by the automated trading are: portfolio balancing and planning, portfolio rebalancing, liquidity screening, and tax implementation.

Thus it is pre-mature to conclude that the buy side financial industry is highly automated. What is currently observed as automated is in fact only auxiliary functions, such as identifying stocks whose P/E ratios are lower than the $5^{\text {th }}$ percentile of the market and then buying them. This function had already been implemented in New York Security Exchange (NYSE) in the 1980s. A more important mission for buy side automation is, for example: what P/E percentile an investor should pursue to maximize the Sharpe ratio of the investor, while also meeting other constrains: tax, liquidity, term, etc.

The buy side automation is a dilemma: it should be implemented, but it is very difficult to achieve such substitution. Buy side automation should replace human being investment process, because the latter has a great number of disadvantages.

First, investment managers have communication gap when facing clients. They might not fully understand the clients' needs due to the different ways of description and personal weight of issues in their minds. For example, when a client makes the expression of hoping her portfolio can be a little aggressive, the manager regard this as $1-2 \%$ higher than the broad equity market index; but the client regards this as $1-2 \%$ higher than the typical return of a bank's savings account. The difference between what the client was expressing and what the asset manager was recording turns out to be more than $5 \%$.

Second, clients are very likely more honest when facing a computer. They address their needs to an investment advising app in a more candid way. However, facing asset managers, clients are usually restricted by many psychological impacts, such as worrying about privacy, being uncomfortable about presenting the financial difficulty, and so on.

Third, investment managers more often use a one-size-fits-all method to treat similar clients. Though managers are required to accommodate individual investor's need, the industry regulation does not prevent them from group similar clients and only use slightly different portfolios for a certain group of clients. Well-known funds typically use a 3 by 3 matrix to describe clients' targets: from small to large equity, and from value to growth equity.

Fourth, investment managers as human beings are subject to cognitive and behavioral biases. These widely-cited biases include anchoring bias, status quo, mental framing, over-confidence, representative bias, loss aversion, herding behavior, hindsight bias, illusion of control, and so on so forth. Machines are not prone to such limits: they execute stop loss orders in a perfectly disciplined way; or would they be affected by recent news.

Fifth, investment managers as human beings are prone to unfairness, personal preference, untransparency, slow execution speed, computation error, or personal limit of time and energy. Computers on the other hand are fast, precise, fair, transparent, error-free, and full-time available. Boehmer, Fong, and Wu (2015) conclude that algorithmic trading improves liquidity and market efficiency, though it also increases volatility. Chaboud, Chiquoine, Hjalmarsson and Vega (2013) suggest that algorithmic trading causes an improvement in price efficiency in the FOREX market.

Sixth, algorithmic trading improves market quality and "should be encouraged" (Hendershott, Jones, \& Menkveld, 2016). They find that "For large stocks in particular, algorithmic trading narrows spreads, reduces adverse selection, and reduces trade-related price discovery. The findings indicate that algorithmic trading improves liquidity and enhances the informativeness of quotes." Consistently, Lyle and Naughton (2015) concluded that “...enhanced liquidity provider monitoring, and not simply increases in algorithmic trading activity, has led to improvements in market quality on the order of tens of billions of dollars a year. This implies that policies facilitating algorithmic trading liquidity provision rather than liquidity taking are more likely to generate improvements in market quality, at least up to a point."

Yet given all the above-mentioned upsides of buy side automation, it is very difficult to do achieve such substitution from human to machine. This is mainly because:

First, clients' education level and limited rationality set a limit to the quality of model parameter inputs. Facing a long list of questions addressing the risk preferences, return targets, and liquidity needs, investors would hardly 
maintain a consistent standard and level of carefulness to answer them. Investors' answers at the moment of inputting the parameters of the investments advising model are also affected by their short term financial dynamics. Thus, non-financial professionals might hold a lower stability in terms of their investment rationality.

Second, the computer algorithms are not completely reliable: program bugs, connection issues, high frequency trading problems, and algorithm errors are frequently seen. Unknown errors and unforeseeable problems might lead to real loss. The large liability of FXCM caused by the Swiss National Bank announcement is an example. Computer-based trading programs on January $15^{\text {th }}, 2015$ failed to foresee the event and failed to execute the stop loss orders. This led to huge loss for the famous FOREX broker.

Third, the financial industry has a strong sentiment on the unemployment brought by such buy side automation. According to the U.S. Department of Labor, the financial services and insurance sectors employed 6.08 million people in 2015. 920,700 people were employed in the securities and investment sector at the end of 2015. Buy side automation significantly affects the position availability in this industry, especially for financial advisors, wealth managers, financial planners, fund managers, and administrative assistants.

This paper is organized as follows: the second section discusses the model inputs; the third section presents the model; and the last section highlights the model limits and the way to implement the model in genuine trading.

\section{Methodology}

The model includes three components: the pre-asset selection planning, the asset selection and execution, and the post-execution portfolio management.

The pre-asset selection planning component includes the inputs of return target, risk profile, liquidity profile, legal concerns, tax profile, unique needs, and asset weights for an empty portfolio.

The asset selection and execution component includes the algorithm of asset picking and trading. As this is usually what the buy side automation focuses on and there are numerous researches and practices on this topic, my paper treats this as a black box with endogenous outputs.

The post-execution portfolio management includes the portfolio rebalancing and risk management. It is not a single recursive solution of the first two steps above, but a different process with the given portfolio, instead of an empty portfolio.

To begin with, the client needs to input the investable asset basis and the gap between cash inflow and cash outflow as the demand of return. Therefore, the ratio of the demand of return by dollar amount $R(D)^{t}$ divided by asset basis would be the demand of return rate. The asset basis that generates the future return is from the previous period $\left(A^{t-1}\right)$. The demand of return of the portfolio $\left(R_{p}^{t}\right)$ should of course have the lower bound of the risk-free interest rate at the current period $\left(R_{f}^{t}\right)$.

$$
R_{p}^{t}=\max \left(\frac{R(D)^{t}}{A^{t-1}}, R_{f}^{t}\right)
$$

The client also needs to input the risk profile. This is comprised of two factors: the ability to take risk and the willingness to take risk. The risk profile should end up being the lower of the two. To make the input parameter close to the genuine questionnaire, this paper does not solicit the direct answer from clients in terms of the standard deviation $\left(\sigma_{p}^{t}\right)$. Rather, clients can deliver the input of maximum drawdown $\left(M D D_{t}\right)$ and the frequency of that to occur. We can explicitly assume that clients expect the likelihood of loss be no more than 5\%. We can also assume that the client's risk preference is a stable variable that does not vary in the short run, so the $\mathrm{Z}$ score is a constant.

$$
M D D_{t}=\left(R_{p}^{t}-Z \sigma_{p}^{t}\right) A^{t-1}
$$

Therefore, the risk profile of the client is in fact:

$$
\sigma_{p}^{t}=\frac{R_{p}^{t}}{Z}-\frac{M D D_{t}}{Z A^{t-1}}
$$

Equation (3) is consistent with the modern portfolio theory that the risk and return of the portfolio should keep a linear relationship, as the portfolio is regarded as including a group of risky assets and a single risk-free asset. We regard the asset basis excludes the financial instruments that do not meet the client's other needs, such as the restrictions from liquidity, tax, term and legal perspective. In the real world, we can add dummy valuables $\left(\begin{array}{lll}D_{1} & \ldots & D_{n}\end{array}\right)$ to convert the asset universe $(\mathbb{A})$ into the feasible asset pool $(\vec{A})$ in the following way: 


$$
\vec{A}=(\vec{D}) \mathbb{A}=\left(\begin{array}{lll}
D_{1} & \ldots & D_{n}
\end{array}\right)\left(\begin{array}{c}
\mathbb{A}_{1} \\
\vdots \\
\mathbb{A}_{n}
\end{array}\right)
$$

In the second step of the buy side automation, we can match the assets in the market with the client's required return and risk tolerance, which are $R_{p}^{t}$ and $\sigma_{p}^{t}$ respectively, assuming that the combination of $R_{p}^{t}$ and $\sigma_{p}^{t}$ does not go beyond the efficient frontier. If a client unrealistically chooses a combination that is to the northeast of the efficient frontier, the algorithm needs to advise the client to revise the needs.

In the third step, which is the portfolio rebalancing, this algorithm finds the balance between the mismatch of risk and return, and the transaction cost of sticking to such risk and return relationship as planned. While it is always preferred to have the portfolio target the ideal risk and return goals, frequent position adjustments can build up high transaction cost $\left(T C^{t+1}\right)$. This cost helps aim the gross return yet make the portfolio deviate from the ideal net return $\left(\left\|R_{p}^{t+1}-R_{p}^{t}\right\|\right)$. Thus the following condition must be met before a rebalance happens:

$$
T C^{t+1} \leq\left\|R_{p}^{t+1}-R_{p}^{t}\right\| \vec{A}
$$

Therefore, the post transaction cost portfolio return is:

$$
r_{p}^{t+1}=R_{p}^{t+1}-T C^{t+1}
$$

\section{Algorithm}

We have set the problem of asset management in section two, that is to maximize the return subject to the maximum drawdown considering portfolio rebalancing, or:

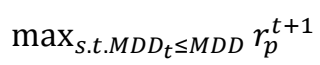

Specifically, the problem is:

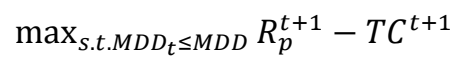

which can be updated to:

$$
\max _{\text {s.t. } \sigma_{p}^{t} \leq \sigma_{p}} R_{p}^{t+1}-T C^{t+1}
$$

And further:

$$
\max _{\text {s.t. } \sigma_{p}^{t} \leq \sigma_{p}}\left(\max \left(\frac{R(D)^{t}}{A^{t-1}}, R_{f}^{t}\right)-T C^{t+1}\right)
$$

We eliminate the parameters that are not the initial inputs from the clients. This would make the optimal solution being associated with only the following variables: $M D D, Z, R(D)$, and $A . R_{f}^{t}$ and $T C^{t+1}$, which are the risk-free interest rate and the transaction cost, should not be required for the clients, yet the algorithm should be able to receive a quote from the market. Therefore the problem is updated to:

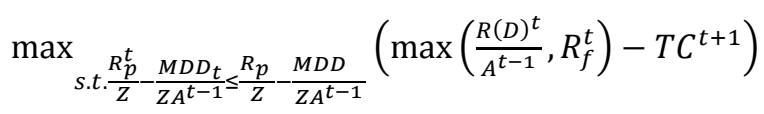

Assume that the client is reasonably advised so she/he understands that she/he should solicit a return higher than the risk-free interest rate level. The problem is then updated to:

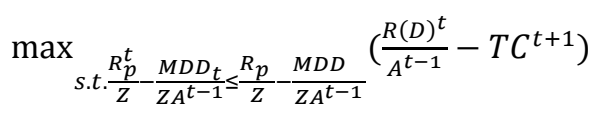

And further:

$$
\max _{\text {s.t. } R_{p}^{t} \leq R_{p}}-\frac{M D D}{A^{t-1}}+\frac{M D D_{t}}{A^{t-1}}\left(\frac{R(D)^{t}}{A^{t-1}}-T C^{t+1}\right)
$$

Given the fact that return is bounded by the upper bound of risk in an efficient market, the problem can be updated to:

$$
\left\{\begin{array}{c}
r_{p}^{t+1}=\frac{R(D)^{t}}{A^{t-1}}-T C^{t+1} \\
R_{p}^{t}=R_{p}-\frac{M D D}{A^{t-1}}+\frac{M D D_{t}}{A^{t-1}} \\
R_{p}^{t}=\max \left(\frac{R(D)^{t}}{A^{t-1}}, R_{f}^{t}\right) \\
r_{p}^{t+1}=R_{p}^{t+1}-T C^{t+1}
\end{array}\right\}
$$


By solving it, the buy side automation problem is now the problem of searching a group of asset that meet the requirement rate of return presented as follows:

$$
r_{p}^{t+1}=R_{p}-\frac{M D D}{A^{t-1}}+\frac{M D D_{t}}{A^{t-1}}-T C^{t+1}
$$

A rearranging result is:

$$
r_{p}^{t+1}=R_{p}-\left(\frac{M D D-M D D_{t}}{A^{t-1}}+T C^{t+1}\right)
$$

This solution should be refreshed per the client's request and according to the market dynamics.

\section{Caveats Concluding Remarks}

So far there is limited literature regarding the automation of financial industry. Currently available researches are mainly about the impact of the use of algorithmic trading on market efficiency, quality and liquidity. This paper provides a model of automated investments procedure to detect the possibility of substituting the human-based portfolio management with a machine-dominated process. The major contribution of this research is the algorithm of discretionary, which is the major obstacle of the machine-based portfolio control. The conclusion of this paper can serve as the logic flow of the investment management program.

The solution of the buy side automation algorithm, which is presented in Equation (16), provides a single linear form with a single goal: searching for an asset that generates a return of

$$
R_{p}-\left(\frac{M D D-M D D_{t}}{A^{t-1}}+T C^{t+1}\right)
$$

The return is the client target return $R_{p}$ being compromised by two components: the $95 \%$ confidence level of reserving a return no less than the asset basis excluding the maximum drawdown; and the transaction cost. In other words, holding an asset with expected return of $R_{p}$ and corresponding risk is equivalent to holding an asset with expected return of $R_{p}-\frac{M D D-M D D_{t}}{A^{t-1}}$ without risk.

The algorithm derived in this paper is not without intrinsic limit. The following assumptions employed in the paper are the major obstacles of perfectly precise modeling in the real world.

First, the single aim model solution suggests that the algorithm only needs to search for assets with the deterministic return. The risk target is embedded within the goal of return. This requires a one to one mapping between return and risk, or an efficient market in which the efficient frontier is a monotonically increasing function. In the real market, this might not be the case. Pricing anomalies frequently bring investors assets that are associated with high risk but low return.

Second, when converting the maximum drawdown to standard deviation, the algorithm implicitly assumes normality of asset return distribution. However, it is widely-agreed that non-zero skewness and excess kurtosis are normally seen in the pool of financial instruments.

The first obstacle can be embedded in the algorithm by adding a new layer of asset return screening. This way the assets that fall into the area southwest to the efficient frontier can be excluded from the pool. The second obstacle is apparently caused by the form of the probability distribution function of the Gaussian distribution. In this case, it is possible to consider using other forms of distribution to allow for the exogenous inputs at higher moments to better describe the asset returns. In this case, copula can be used to analyze such possible distribution. This can also be a further research in the future to make the model derived in this study more realistic and applicable.

\section{References}

Ansari, A., \& Riasi, A. (2016). Modelling and evaluating customer loyalty using neural networks: Evidence from startup insurance companies. Future Business Journal, 2(1), 15-30. http://dx.doi.org/10.1016/j.fbj.2016.04.001

Boehmer, E., Fong, K. Y. L., \& Wu, J. (2015). International Evidence on Algorithmic Trading. AFA 2013 San Diego Meetings Paper. http://dx.doi.org/10.2139/ssrn.2022034

Cartea, A., Donnelly, R. F., \& Jaimungal, S. (2014). Algorithmic Trading with Model Uncertainty. Working paper. 
http://dx.doi.org/10.2139/ssrn.2310645

Cartea, A., \& Jaimungal S. (2016). Algorithmic Trading of Co-integrated Assets. International Journal of Theoretical and Applied Finance, 19(6). http://dx.doi.org/10.1142/S0219024916500382

Chaboud, A., Chiquoine, B., Hjalmarsson, E., \& Vega, C. (2013). Rise of the Machines: Algorithmic Trading in the Foreign Exchange Market. Journal of Finance, 69(5), 2045-2084. http://dx.doi.org/10.1111/jofi.12186

Hendershott, T., Jones, C. M., \& Menkveld, A. J. (2016). Does Algorithmic Trading Improve Liquidity? Journal of Finance, 66(1), 1-33. http://dx.doi.org/10.1111/j.1540-6261.2010.01624.x

Lyle, M. R., \& Naughton, J. P. (2015). How Does Algorithmic Trading Improve Market Quality? Northwestern University working paper. http://dx.doi.org/10.2139/ssrn.2587730

Shah, S., \& Brorsen, B. W. (2011). Electronic vs. Open Outcry: Side-by-Side Trading of KCBT Wheat Futures. Journal of Agricultural and Resource Economics, 36(1), 48-62.

\section{Copyrights}

Copyright for this article is retained by the author(s), with first publication rights granted to the journal.

This is an open-access article distributed under the terms and conditions of the Creative Commons Attribution license (http://creativecommons.org/licenses/by/4.0/). 